\title{
Sinus node recovery after explantation of Amplatzer septal occluder: A word of caution
}

Sameh M. Said, MBBCh, MD, FACS, ${ }^{\mathrm{a}}$ Sandeep Sainathan, MD, ${ }^{\mathrm{a}}$ Carlos Miranda, MD, Varun Aggarwal, MD, ${ }^{\mathrm{b}}$ and John Bass, MD, ${ }^{\mathrm{b}}$ Minneapolis, Minn, and Fargo, ND

From the Divisions of ${ }^{\mathrm{a} P e d i a t r i c}$ Cardiovascular Surgery, and ${ }^{\mathrm{b}}$ Pediatric Cardiology, Masonic Children's Hospital, University of Minnesota, Minneapolis, Minn; and ${ }^{\mathrm{c} S a n f o r d ~ P e d i a t r i c ~ C a r d i o l o g y, ~ F a r g o, ~ N D . ~}$

Disclosures: S.M.S. is a consultant for Cryolife, Abbott, and Stryker. All other authors reported no conflicts of interest.

The Journal policy requires editors and reviewers to disclose conflicts of interest and to decline handling or reviewing manuscripts for which they may have a conflict of interest. The editors and reviewers of this article have no conflicts of interest.

Received for publication Sept 8, 2021; accepted for publication Dec 4, 2021; available ahead of print Jan 19, 2022. Address for reprints: Sameh M. Said, MBBCh, MD, FACS, Division of Pediatric Cardiovascular Surgery, Masonic Children's Hospital, University of Minnesota, 2450 Riverside Ave S, Academic Office Building, 521, Minneapolis, MN 55454 (E-mail: ssaid@umn.edu).

JTCVS Techniques 2022;12:166-9

2666-2507

Copyright $(2022$ The Author(s). Published by Elsevier Inc. on behalf of The American Association for Thoracic Surgery. This is an open access article under the CC BY-NC-ND license (http://creativecommons.org/licenses/bync-nd/4.0/).

https://doi.org/10.1016/j.xjtc.2021.12.010

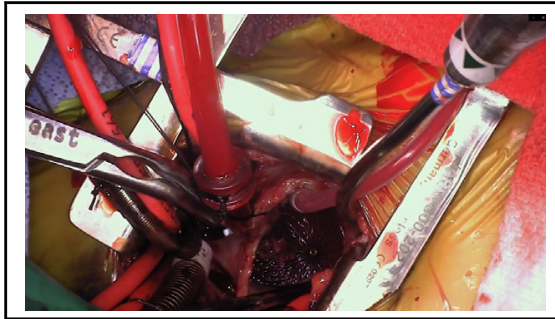

The device is visualized through right atriotomy. Notice the clot on the device surface.

CENTRAL MESSAGE

Large devices used for closure of atrial septal defects should be used with caution. While it is rare, sinus node dysfunction can occur, and the device should be removed to restore sinus rhythm.

See Commentary on page 170.
In the current era, transcatheter device closure is becoming the first-line therapy for anatomically feasible secundum atrial septal defect (ASD II). The overall complication rate is low, with the most common being device malposition/ embolization and residual shunts. Cardiac perforations are rare, but atrial arrhythmias, thrombus formation, endocarditis, and atrioventricular valve regurgitation have been reported.

We are not aware of a report of sinus node dysfunction in pediatric patients after device closure of ASD II. We present a 13-month-old boy who underwent device closure of multiple ASD II and developed a sinus node dysfunction that recovered after device removal.

Informed consent was obtained from the parents to publish this report. No institutional review board approval was required according to our institution policy due to the single case report nature of the manuscript.

\section{CASE REPORT}

A 13-month-old, 6.4-kg boy with duplication of short arm of chromosome 3 and Dandy-Walker syndrome underwent hybrid closure of multiple ASD II with a 25-mm cribriform Amplatzer device (Abbott Laboratories). The atrial septum was multifenestrated, with the largest defect measuring $7.5 \mathrm{~mm}$ in diameter, and at least 2 other small defects were identified. The patient's baseline heart rhythm was sinus; however, he developed persistent junctional rhythm with bradycardia in the immediate postprocedure period. Isoproterenol was used to counteract this bradycardia. Repeat attempts at weaning isoproterenol resulted in recurrence of his bradycardia and persistence of junctional rhythm. The device itself appeared to be in a good position with no residual shunts.

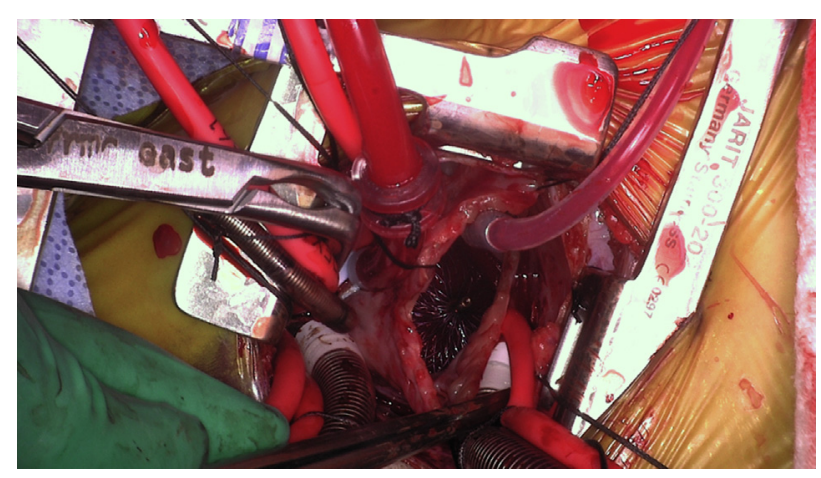

FIGURE 1. Intraoperative photo showing, through a right atriotomy, the atrial septal closure device occupying the majority of the right atrium. Notice the clot on the device surface. 


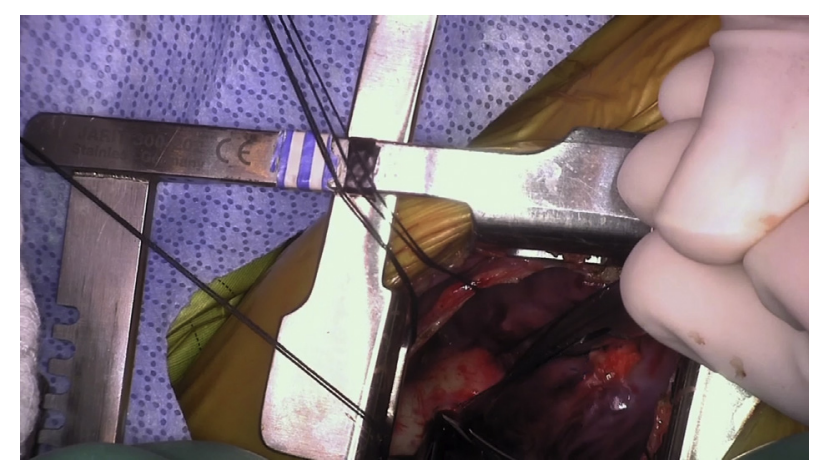

VIDEO 1. The current video shows removal of an Amplatzer device that was used to close a fenestrated atrial septum in a 13-month-old child. The procedure was performed via a vertical axillary thoracotomy using normothermic cardiopulmonary bypass and a bovine pericardial patch was used to close the atrial septal defects after transforming them into one a large defect. Video available at: https://www.jtcvs.org/article/S2666-2507(22) 00023-2/fulltext.

After several discussions among our team, decision was made to proceed with removal of the device. Three days after the initial procedure, the patient was taken to the operating room and through a vertical axillary thoracotomy and using normothermic cardiopulmonary bypass, we were able to visualize the device, which appeared to occupy the majority of the right atrium (Figure 1 and Video 1). The device had multiple clots on both its right and left atrial surfaces, which were most likely related to a combination of a slow rhythm and absence of the atrial kick.

The device was removed without difficulty, and a bovine pericardial patch was used to close the ASDs after transforming them into one large defect (Figure 2, $A$ and $B$ ). We also placed permanent atrial epicardial pacemaker leads in case a permanent pacemaker would be needed later. The patient had an uncomplicated postoperative course, and he regained his normal sinus rhythm 3 days later. Although one can argue that the rhythm recovered 3 days after surgery and watchful waiting may have been an option, we were afraid of losing a good window of normal rhythm recovery if we waited longer. The patient was discharged 10 days after his initial procedure without needing a permanent pacemaker.

\section{DISCUSSION}

In a meta-analysis of 28,142 patients from 203 studies, the incidence of heart block was $0.2 \%$ with no report of sinus node dysfunction in any of these patients. ${ }^{1}$ Transcatheter and intraoperative device closure are feasible, effective, and safe methods for the treatment of ASDs in children younger than 3 years of age, ${ }^{2}$ less than $10 \mathrm{~kg},{ }^{3}$ and with no mortality, failure of the procedure, device embolization, thromboembolism, or pericardial effusion. ${ }^{4}$ Transient or complete atrioventricular block due to device impingement has been rarely reported.

Recently, the use of septal occluder devices has extended to include multiple defects and cases in which the atrial septum is fenestrated, such as the current case. ${ }^{5}$ Farhaj and colleagues ${ }^{6}$ have diverse layouts and classification of multihole secundum ASD that can help to choose different techniques and proper devices of different kinds to achieve safer and better occlusion results.

Placement of a large device (a clear definition is unknown) that covers the entire atrial septum theoretically can eliminate all the shunts; however, the long-term impact of these large devices on the smaller hearts of infants and young children is unknown. In our patient, the device that was used was a 25-mm Amplatzer Cribriform occluder (Abbott Laboratories), which is a relatively large device for a 6.4-kg child. Theoretically, a larger device will affect predominantly the atrioventricular node due to the position of the device (Figure E1), causing heart block rather than a sinus node dysfunction. We hypothesize that the larger device may have caused sinus node dysfunction by stretching

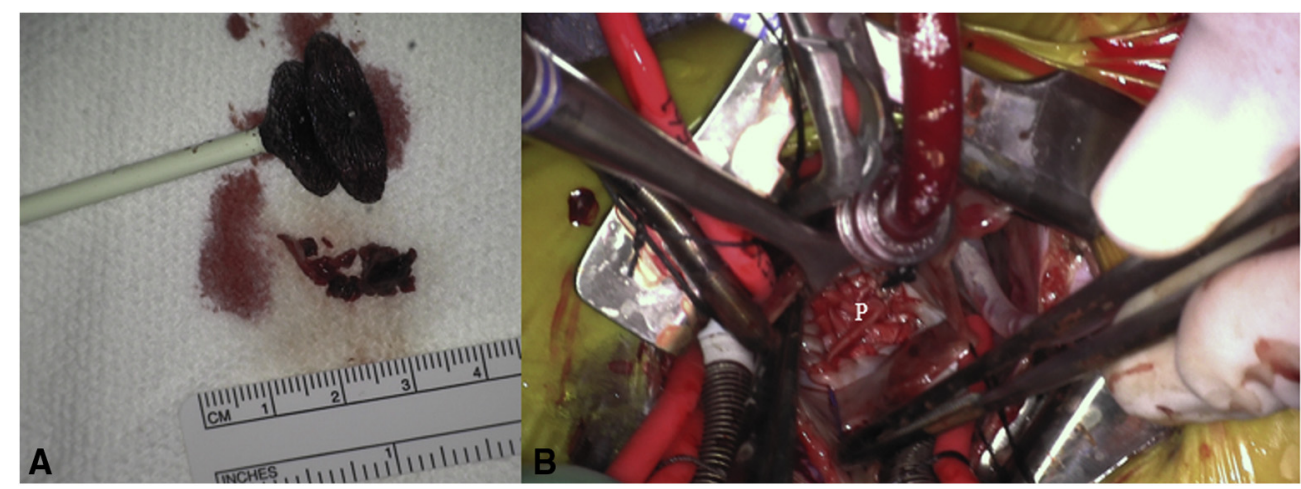

FIGURE 2. Intraoperative photos showing (A) the explanted Amplatzer device with associated clots, and in (B) the view through right atriotomy after bovine pericardial patch closure of the atrial septal defects. $P$, Pericardial patch. 
the area of the superior vena caval/right atrial junction where the sinoatrial node is located, and/or partial obstruction of the coronary sinus with subsequent cardiac edema, which was noticed upon re-exploration resulting in sinus node dysfunction.

In conclusion, we like to emphasize the avoidance of using large septal occluder devices, discrepant to the size of the atrial cavities of the child, and while sinus node dysfunction is a rare occurrence, removal of the device should be strongly considered if this complication is encountered.

We thank Mr Mahmoud Said, Minnetonka High School, Minneapolis, Minn, for his assistance in editing the video provided for the current manuscript.

\section{References}

1. Abaci A, Unlu S, Alsancak Y, Kaya U, Sezenoz B. Short and long term complications of device closure of atrial septal defect and patent foramen ovale: metaanalysis of 28,142 patients from 203 studies. Catheter Cardiovasc Interv. 2013 8:1123-8.

2. Han Y, Zhang X, Zhang F. Transcatheter and intraoperative device closure of atrial septal defect in infants under three years of age. J Cardiothorac Surg. 2020;15:9.

3. Wyss Y, Quandt D, Weber R, Stiasny B, Weber B, Knirsch W, et al. Interventional closure of secundum type atrial sepal defects in infants less than 10 kilograms: indications and procedural outcome. J Interv Cardiol. 2016;29:646-53.

4. Sharma B, Pinto R, Dalvi B. Transcatheter closure of atrial septal defect in symptomatic children weighing $\leq 10 \mathrm{~kg}$ : addressing unanswered issues from a decade of experience. Ann Pediatr Cardiol. 2020;13:4-10.

5. Mehta S, Hill JA, Qureshi AM, Latson LA, Prieto LR. Helex device closure of multiple atrial septal defects. Catheter Cardiovasc Interv. 2014;84:204-10.

6. Farhaj Z, Hongxin L, Wenbin G, Zhang WL, Liang F, Zhang HZ, et al. Device closure of diverse layout of multi-hole secundum atrial septal defect: different techniques and long-term follow-up. J Cardiothorac Surg. 2019;14:130. 


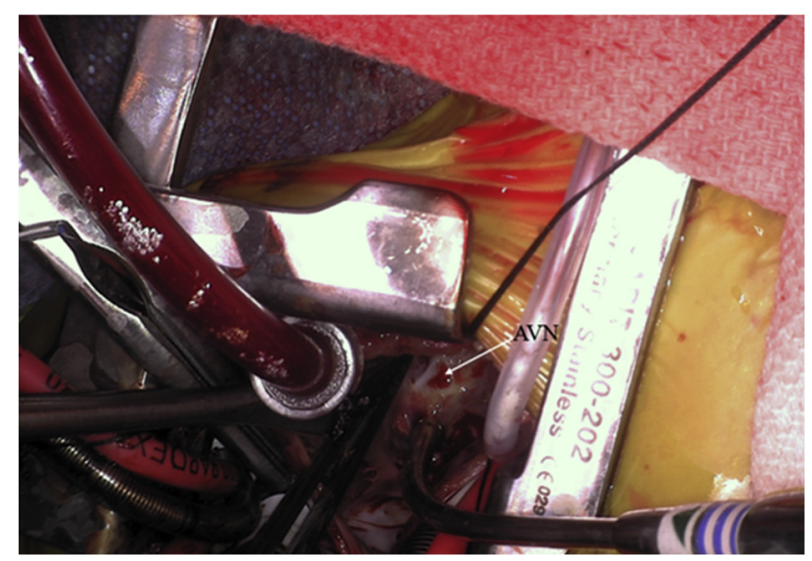

FIGURE E1. Intraoperative photo showing, through a right atriotomy, the area of the atrioventricular node after the device is removed. Notice the bruises in this area, which explain why these patients can develop heart block. AVN, Atrioventricular node. 